\title{
Konfigurasi Cekungan Barito Kalimantan Selatan Berdasarkan Analisis Data Gayaberat
}

\author{
Eddy Mirnanda* \\ Pusat Penelitian dan Pengembangan Geologi Kelautan, \\ Jln. Dr. Djundjunan No. 236 Bandung, 40174, Indonesia \\ *Email : e_mirnanda@yahoo.co.id
}

\section{ABSTRACT}

The Barito Basin is rather oval with the main axis trending Northeast of the Southwest. Basin section is not symmetrical, the east wing is steep while the west wing is relatively flat. Right on the main shaft of the basin with an anomaly value of around $-25 \mathrm{mGal}$, the bedrock of Granite as a bedrock of pre-Tertiary age reaches a depth of approximately $11 \mathrm{~km}$ below the surface. In this basin, the Old Tertiary sedimentary rock is $5 \mathrm{~km}$ thick and the Young Tertiary sediment above it is $6 \mathrm{~km}$ thick. To the east the Young Tertiary sediments are increasingly thinning and ending with the emergence of Old Tertiary sediments due to the drag of igneous intrusion. To the west, the Bouguer gravity anomaly value slowly rises to $+40 \mathrm{mGal}$, the possibility of Granite bedrock getting closer to the surface around 6 to $7 \mathrm{~km}$, on top of which is overlapped by Old Tertiary sediments with a thickness of $5 \mathrm{~km}$ covered by Young Tertiary sediments as thick as 1 to $2 \mathrm{~km}$.

Based on the subsurface mass density model analysis, it is found that the tertiary and pre-Tertiary sediments with a density of $2.20 \mathrm{gr} / \mathrm{cm}^{3}$ and $2.40 \mathrm{gr} / \mathrm{cm}^{3}$ respectively are the top layer, then followed by rocks with a density of $2.68 \mathrm{gr} / \mathrm{cm}^{3}$ as a reflection Granitic bedrock and $3.10 \mathrm{gr} / \mathrm{cm}^{3}$ represent the Upper Mantle. In addition, Ultrabasa rocks are exposed in the Meratus mountain section which has a density of $2.90 \mathrm{gr} / \mathrm{cm}^{3}$ which is mounted on top of Granitic rocks and is penetrated by Granite intrusion rocks with a density of $2.72 \mathrm{gr} / \mathrm{cm}^{3}$.

Keywords: Pre-Tertiary, Tertiary, Granite, Sediment, Granitic bedrock, Ultrabasa rock, Barito Basin.

\section{ABSTRAK}

Cekungan Barito agak lonjong dengan poros utama berarah Timurlaut - Baratdaya. Penampang cekungan tidak simetris, sayap bagian timur terjal sedang sayap barat relatip datar. Tepat di bagian poros utama cekungan dengan nilai anomali sekitar $-25 \mathrm{mGal}$, batuan dasar Granit sebagai batuan dasar berumur pra-Tersier mencapai kedalaman kurang lebih $11 \mathrm{~km}$ di bawah permukaan. Di bagian cekungan ini, diisi batuan sedimen Tersier Tua setebal $5 \mathrm{~km}$ dan sedimen Tersier Muda diatasnya setebal $6 \mathrm{~km}$. Ke arah timur sedimen Tersier Muda makin menipis dan diakhiri oleh kemunculan sedimen Tersier Tua akibat seretan intrusi batuan beku. Ke arah barat, nilai anomali gayaberat Bouguer naik secara perlahan mencapai +40 mGal, kemungkinan batuan dasar Granit makin mendekati permukaan sekitar 6 sampai $7 \mathrm{~km}$, diatasnya ditindih oleh sedimen Tersier Tua dengan tebal $5 \mathrm{~km}$ yang tertutup oleh sedimen Tersier Muda setebal 1 sampai $2 \mathrm{~km}$.

Berdasarkan analisis model rapat massa bawah permukaan diperoleh bahwa sedimen berumur Tersier dan pra-Tersier dengan rapatmassa masing-masing 2,20 gr/ $\mathrm{cm}^{3}$ dan 2,40 gr/ $\mathrm{cm}^{3}$ merupakan lapisan paling atas, kemudian disusul oleh batuan dengan rapatmassa 2,68 gr/ $\mathrm{cm}^{3}$ sebagai cerminan batuan dasar Granitik dan 3,10 gr/ $\mathrm{cm}^{3}$ mewakili Mantel Atas. Selain itu batuan Ultrabasa yang tersingkap di bagian pegunungan Meratus yang memiliki rapatmassa 2,90 gr/ $\mathrm{cm}^{3}$ yang menumpang di atas batuan Granitik dan diterobos oleh batuan intrusi Granit dengan rapatmassa 2,72 gr/ $\mathrm{cm}^{3}$.

Kata Kunci: pra-Tersier, Tersier, Granit, Sedimen, batuan dasar Granitik, batuan Ultrabasa Cekungan Barito 


\section{PENDAHULUAN}

Cekungan Barito merupakan salah satu cekungan penghasil minyak bumi di Indonesia, tepatnya di pulau Kalimantan bagian tenggara yang sebagian besar termasuk dalam wilayah daerah Tingkat-1 Provinsi Kalimantan Selatan. Cekungan Barito mempunyai luas penyebaran sebesar kurang lebih $75.000 \mathrm{~km}^{2}$ dengan ketebalan batuan sedimen Tersier sekitar 2000 - 5000 meter.

Telah banyak ladang-ladang penghasil minyak bumi yang telah diketemukan disini terutama hasil dari kegiatan survei seismik yang telah dilakukaan oleh perusahaan minyak nasional maupun asing di wilayah ini. Kegiatan seismik ini telah banyak dilakukan di lapangan minyak Tanjung atau lapangan minyak Warukin terutama untuk mencari jebakan-jebakan minyak bumi pada batuan sedimen Tersier yang mengisi Cekungan Barito ${ }^{[1][2]}$.

Untuk mempermudah usaha pengembangan beberapa ladang minyak baru, maka perlu dilakukan penelitian gayaberat secara regional di wilayah Cekungan Barito dan lainnya untuk mendapatkan konfigurasi cekungan tersebut dengan mendeteksi kedudukan batuan dasar Granit yang mendasari cekungan tersebut.

Tujuan penelitian gayaberat ini adalah untuk mengetahui secara regional gambaran konfigurasi Cekungan Barito sebagai cekungan hidrokarbon berdasarkan analisis data gayaberat. Dengan diketahuinya nilai rapatmassa batuan, kedalaman serta ketebalan batuan sedimen, struktur geologi yang berkembang, dan konfigurasi batuan dasar Granit, maka diharapkan konfigurasi Cekungan Barito di bawah permukaan dapat ditentukan.

\section{Geologi Daerah Penelitian}

Cekungan Barito terletak di bagian tenggara pulau Kalimantan. Cekungan ini dibatasi oleh Tinggian Meratus pada bagian timur dan pada bagian utara dibatasi oleh Tinggian Pater Noster, di bagian barat dibatasi langsung oleh Paparan Sunda yang sebagian dari bagian lempeng Benua Asia, sedang di bagian selatan berbatasan langsung dengan laut Jawa, seperti tampak lokasi penelitian yang berada di lembar Amuntai, Kalimantan Selatan pada Gambar 1 di bawah ini. 


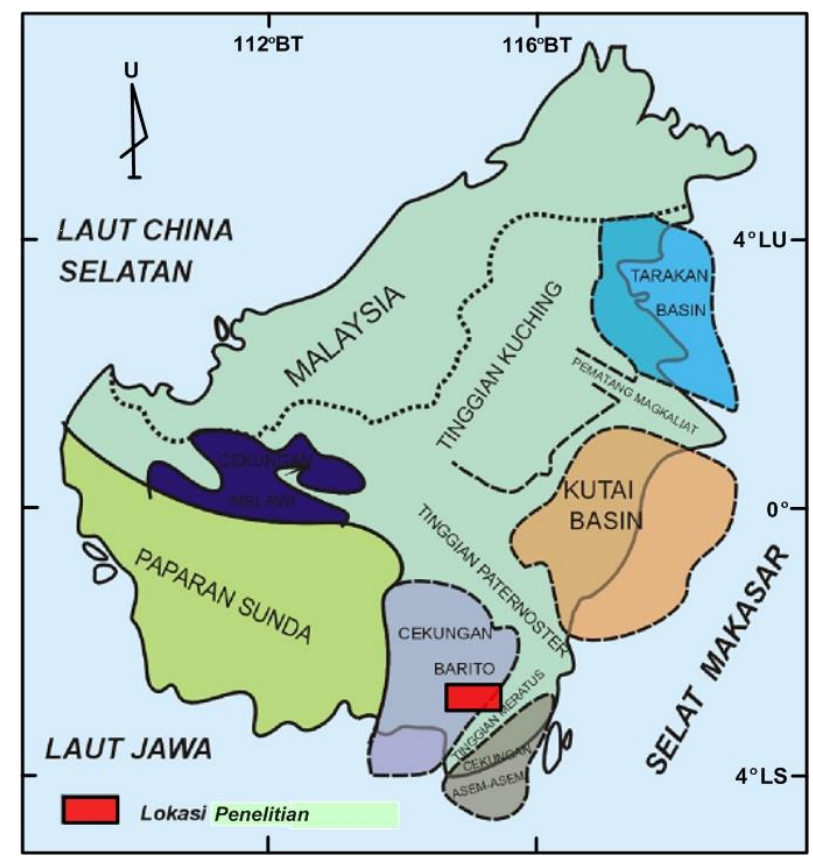

Gambar 1. Lokasi daerah penelitian (kotak warna merah) dan unsur-unsur tektonik Kalimantan ${ }^{[3]}$. .

Hasil dari pemetaan geologi lembar Amuntai, Provinsi Kalimantan Selatan dapat dilihat pada Gambar 2 dibawah ini.

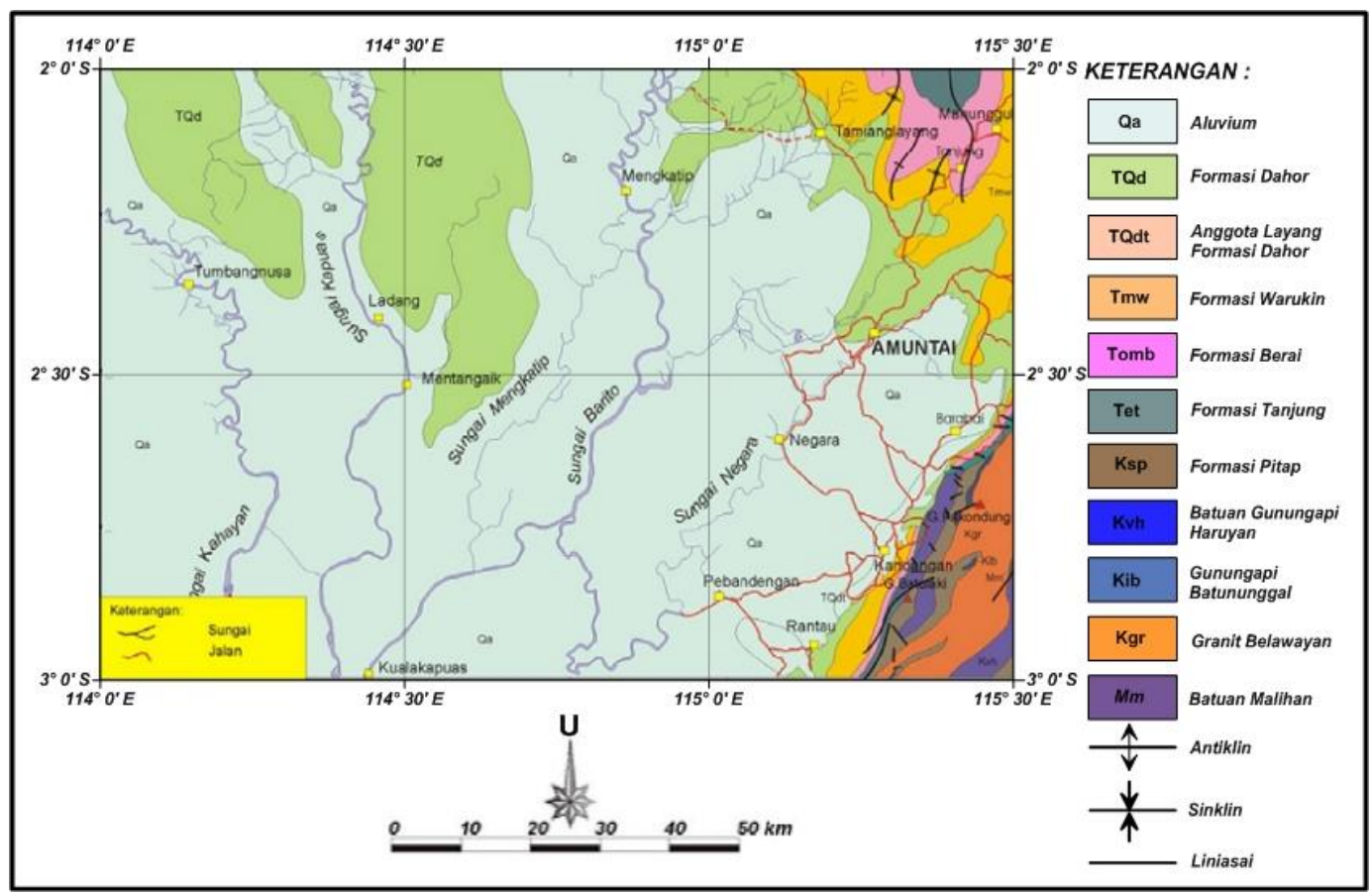

Gambar 2. Peta Geologi Lembar Amuntai, Provinsi Kalimantan Selatan. ${ }^{[4]}$

Secara regional daerah penelitian ini termasuk bagian dari Cekungan Barito yang merupakan suatu sistem fisiografi pegunungan Meratus yang terbentang dengan arah Baratdaya - Timurlaut dan termasuk dalam peta geologi Lembar Amuntai Kalimantan 
Selatan ${ }^{[4]}$. Batuan dasar Cekungan Barito adalah batuan pra-Tersier terdiri dari batuan beku bersifat Granitik dan Andesitik serta batuan malihan terdiri dari perselingan Batulanau dengan Batupasir halus sampai kasar dengan sisipan Konglomerat dan Breksi (Formasi Pitap). Di atas batuan pra-Tersier ini, diendapkan batuan sedimen Tersier yang terdiri dari tua ke muda yaitu Formasi Tanjung, Formasi Berai, Formasi Warukin, Formasi Dahor dan Endapan Kuarter (Aluvium). Kontak antara batuan Pra-Tersier dan batuan sedimen Tersier adalah kontak ketidakselarasan umur, tetapi di beberapa tempat tertentu terdapat kontak ketidakselarasan tektonik. Umur dari batuan sedimen Tersier pengisi Cekungan Barito adalah Eosen sampai Pleistosen. Formasi pembawa bitumen padat di daerah ini adalah Formasi Tanjung yang berumur Eosen dan Formasi Warukin yang berumur Miosen Awal hingga Miosen Tengah ${ }^{[4]}$.

Struktur geologi yang berkembang di daerah penelitian berupa lipatan dan sesar. Sumbu lipatan umumnya berarah Baratdaya-Timurlaut, Pada akhir Kapur terjadi kegiatan tektonik yang besar, akibatnya batuan Mesozoikum terangkat yang kemudian diikuti oleh proses pendataran. Pada Awal Eosen terendapkan Formasi Tanjung dalam lingkungan paralik, dan pada kala Oligosen terjadi genang laut yang membentuk Formasi Warukin dan diendapkan dalam lingkungan paralik ${ }^{[4]}$.

Kegiatan tektonik yang baru diketahui dengan jelas adalah pada paska Miosen, namun diduga kegiatan tersebut telah berlangsung sebelum Tersier. Batuan tertua di daerah ini berupa batuan Malihan yang diterobos oleh batuan Granit yang berhubungan dengan proses penelusupan dan berumur Kapur Awal. Pada waktu yang hampir bersamaan terendapkan Batugamping Orbitolina yang merupakan endapan paparan Karbonat. Batuan-batuan tersebut merupakan alas dari batuan Sedimen Laut yang berumur Kapur Akhir pada cekungan muka. Kegiatan gunungapi berlangsung sampai dengan Kapur Akhir dan berkedudukan menjemari dengan sedimen laut. Pada awal Tersier, kemungkinan terjadi peristiwa tektonik yang disertai dengan pengendapan batuan Sedimen dan Karbonat sebagai endapan tanah muka. Kegiatan magma pada Tersier diduga merupakan paska penelusupan, sedangkan struktur geologi di daerah ini terdiri atas kelurusan dan lipatan yang berarah Timurlaut-Baratdaya ${ }^{[4]}$.

Cekungan Barito bukan merupakan cekungan yang sederhana menurut kejadian tektoniknya, tetapi dapat diklasifikasikan sebagai poli-basin, yaitu berbagai tipe cekungan yang saling bertumpukan ${ }^{[5]}$. Konfigurasi cekungan yang terbentuk sekarang ini merupakan cekungan asimetris, batuan dasar semakin dalam dari barat ke timur, semakin curam mendekati Pegunungan Meratus, terpisah dengan sesar anjak utama yang diperlihatkan sebagai cekungan muka daratan, dengan bagian barat yang lebih besar dinamakan Lereng Barito Barat atau Paparan Barito, dan bagian yang lebih dalam dinamakan Barito Deep, juga disebut sebagai Barito Foredeep.

Dari gambaran seismik terlihat bahwa Cekungan Barito merupakan cekungan muka daratan, yang khas berhubungan dengan pelenturan kerak benua, akibat tabrakan lempeng kontinen Sunda dengan mikrokontinen paparan Pater Noster yang terletak di atas kerak kontinen sehingga terjadi pencuatan tinggian Meratus. Tepat disebelah lereng barat Meratus terjadi proses pengerutan dan penurunan "passive margin" sehingga di bagian ini terbentuk lapisan sedimen yang sangat tebal. Di bagian barat terjadi proses penurunan akibat pelenturan dari kerak benua yang menyebabkan terjadinya pelipatan batuan sedimen model terbuka ${ }^{[6]}{ }^{[7]}$. 


\section{METODE}

Metode Geofisika yang digunakan dalam penelitian ini adalah metode gayaberat dengan menggunakan satu unit alat gravitymeter La Coste \& Romberg tipe G525 dengan nilai pembacaan 0 - $7000 \mathrm{mGal}$ dengan ketelitian $0.01 \mathrm{mGal}$, dan apungan rata-rata kurang dari $1 \mathrm{mGal}$ setiap bulannya. Metode gayaberat menggunakan konsep adanya perbedaan kecil medan gayaberat yang disebabkan distribusi rapatmassa batuan yang tidak merata di kerak bumi. Perbedaan rapatmassa ini akan menimbulkan medan gayaberat tidak merata, yang terukur di permukaan bumi. Sebelum melakukan pengukuran di lapangan, ditentukan terlebih dahulu pembacaan di DG.0 Museum Geologi Bandung. Nilai pengukuran tersebut diturunkan ke titik pangkal (base station) yang ada di Hotel Monica, Amuntai, Provinsi Kalimantan Selatan yang sudah ditentukan oleh Tim terdahulu ${ }^{[8]}$.

Pengukuran gayaberat di daerah Amuntai, Provinsi Kalimantan Selatan telah diperoleh sebanyak 150 data pengamatan gayaberat yang meliputi sebagian dari wilayah Cekungan Barito (tepatnya di lembar Amuntai) pada umumnya terdiri dari rawa-rawa hampir $80 \%$ dan daratan relatif sedikit, pengukuran dilakukan menelusuri sungai-sungai sesuai dengan penyebaran titik pengamatan secara acak dimana spasi rata-rata antara titik pengamatan sekitar 5 sampai $10 \mathrm{~km}$, sedangkan ketinggian titik pengamatan diukur dengan menggunakan alat Mikrobarometer ${ }^{[9][10]}$.

Dari pembacaan peralatan gravitymeter tersebut kemudian dikonversi dengan menggunakan tabel konversi yang sesuai sehingga akan diperoleh hasil pembacaan dalam satuan gayaberat (mGal) dan dilanjutkan ke tahapan koreksi yang meliputi : pasang surut gayaberat (tide correction), apungan alat (drift correction), efek udara bebas (free air correction), efek Bouguer Slab, dan topografi (terrain correction) ${ }^{[11]}$.

Rumus untuk menghitung nilai anomali Bouguer adalah sebagai berikut ${ }^{[11]}$ :

$$
\mathrm{BA}=\mathrm{Gobs}-\mathrm{Gn}-\mathrm{BC}+\mathrm{FAC}+\mathrm{TC}
$$

Dimana :

BA : Anomali Bouguer (mGal)

Gobs : Nilai gayaberat pengamatan (mGal)

$\mathrm{Gn} \quad$ : Nilai gayaberat pada suatu lintang (mGal)

BC : Koreksi Bouguer (mGal)

FAC : Koreksi udara bebas (mGal)

TC : Koreksi medan (mGal)

Hasil reduksi data gayaberat disajikan ke dalam bentuk tabel yang kolom-kolomnya terdiri atas nomor titik amat, bujur, lintang, tinggi, nilai gayaberat pengamatan $\left(\mathrm{G}_{\mathrm{obs}}\right)$ dan anomali Bouguer. Nilai anomali Bouguer yang diperoleh dari persamaan diatas, kemudian dilakukan pengkisian dan pengkonturan menggunakan software sehingga dapat disajikan dalam bentuk peta anomali Bouguer.

Sedangkan pemodelan penampang anomali gayaberat Bouguer menggunakan software sederhana 2,5D dari Talwani berdasarkan atas rapatmassa acuan (background density) adalah $2,68 \mathrm{gr} / \mathrm{cm}^{3}{ }^{[11][12]}$. 


\section{HASIL DAN PEMBAHASAN}

Berdasarkan peta anomali gayaberat Bouguer daerah penelitian yang tampak pada Gambar 3, maka diperoleh hasil survei gayaberat memperlihatkan bahwa secara umum pola anomali gayaberat Bouguer berkisar antara $-25 \mathrm{mGal}$ hingga $+55 \mathrm{mGal}$ menunjukkan pola anomali berarah timurlaut-baratdaya sesuai dengan arah poros pegunungan Meratus di bagian tenggara Kalimantan. Di tempat ini, nilai anomali gayaberat Bouguer sekitar $+55 \mathrm{mGal}$ yang merupakan nilai anomali tertinggi yang diakibatkan oleh adanya penelusupan batuan Beku atau Vulkanik Meratus terhadap batuan Sedimen Tersier Tua diatasnya, termasuk adanya batuan Ultrabasa yang naik mendekati permukaan. Kemudian ke arah baratlaut nilai anomali merendah secara cepat mencapai $-25 \mathrm{mGal}$, yang diduga sebagai batuan dasar Granit berumur pra-Tersier Cekungan Barito yang berada pada posisi paling dalam sekitar $11 \mathrm{~km}$ di bawah permukaan. Di tempat ini juga, cekungan diisi oleh batuan sedimen Tersier Muda setebal $6 \mathrm{~km}$ dan dibawahnya batuan sedimen Tersier Tua setebal $5 \mathrm{~km}$. Makin ke arah barat nilai anomali gayaberat Bouguer mulai naik secara perlahan mencapai $+40 \mathrm{mGal}$, kemungkinan batuan dasar Granit makin mendekati permukaan setebal sekitar $6-7 \mathrm{~km}$ yang diperkirakan terus melampar sampai di sebelah barat daerah penelitian. Di atas batuan dasar, diisi oleh batuan Sedimen Tersier Tua setebal $5 \mathrm{~km}$ yang ditutup oleh batuan Sedimen Tersier Muda setebal $1-2 \mathrm{~km}$. Di bagian baratlaut muncul pola kontur tertutup dengan nilai anomali gayaberat Bouguer merendah sekitar $+15 \mathrm{mGal}$ yang kemungkinan merupakan cekungan setempat (subbasin) sebagai bagian dari Cekungan Barito. Sementara di bagian ujung timurlaut daerah penelitian, dijumpai nilai anomali +25 mGal hingga +40 mGal membentuk pola anomali melingkar terbuka arah utara, tepatnya di sekitar kota Tanjung. Hal ini menunjukkan adanya cekungan sedimen yang berpotensi sebagai penghasil batubara dan hidrokarbon, sedangkan di daerah sekitar pegunungan Meratus menunjukan adanya batuan gunung api dan batuan ultrabasa yang berpotensi sebagai penghasil mineral ekonomis.

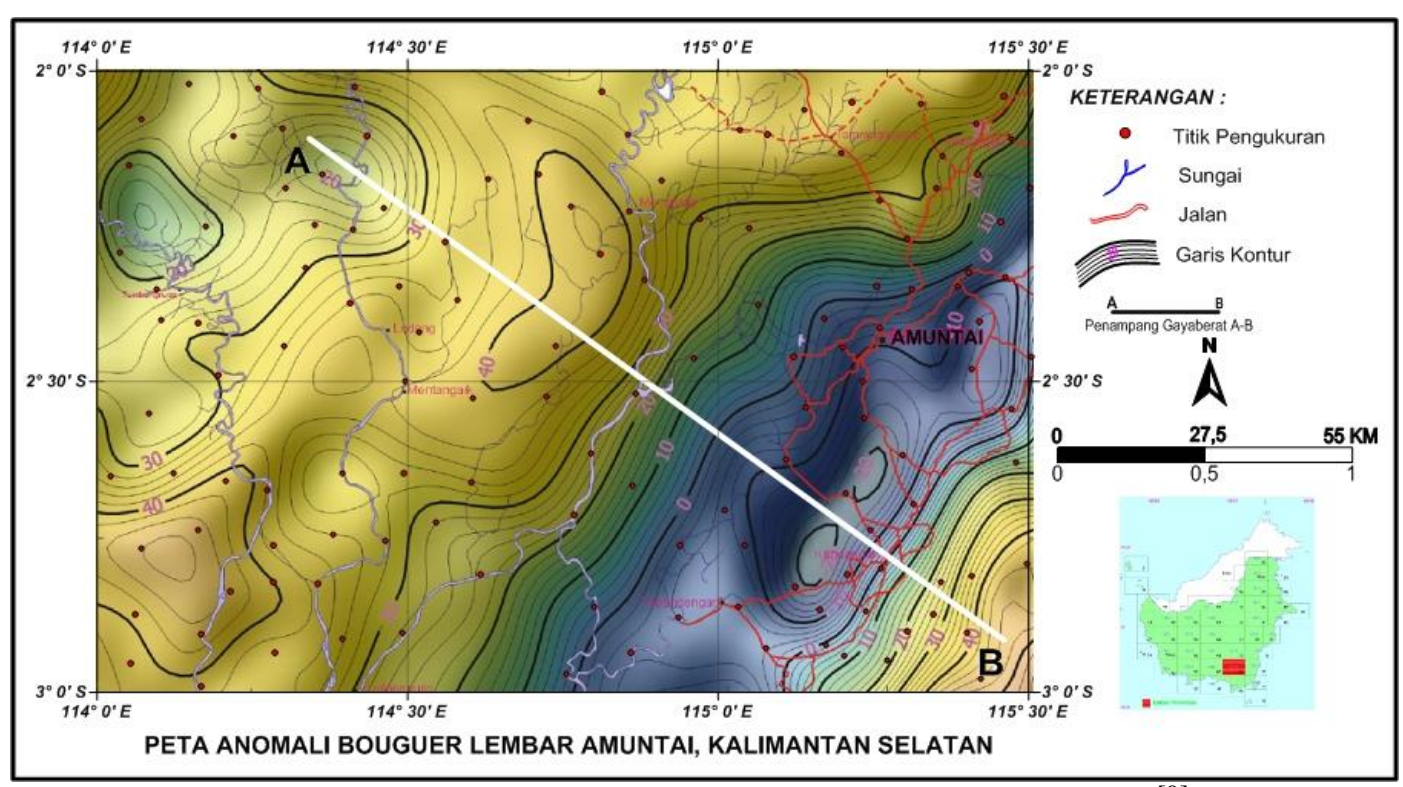

Gambar 3. Peta Anomali Bouguer Lembar Amuntai, Kalimantan Selatan ${ }^{[9]}$. 
Untuk mendapatkan gambaran yang jelas mengenai geologi bawah permukaan (model kerak) di wilayah Cekungan Barito ini, maka dibuatlah sebuah garis lintasan A - B sepanjang kurang lebih $162 \mathrm{~km}$ peta anomali gayaberat Bouguer (Gambar 3) dengan arah lintasan Baratlaut-Tenggara yang tegak lurus dengan arah lajur pegunungan Meratus.

Parameter-parameter yang penting dalam pembuatan model penampang ini berupa rapatmassa (density) batuan dan tebal tiap-tiap perlapisan yang biasanya diperoleh dari sumber lainnya, seperti: data geologi, data bor dan seismik.

Dari model penampang gayaberat lintasan A-B dengan arah tegak lurus poros utama cekungan, maka akan nampak kedua sayap timur-barat cekungan yang tidak simetris, sehingga sayap timur terlihat relatip curam dibandingkan dengan sayap barat relatip landai.

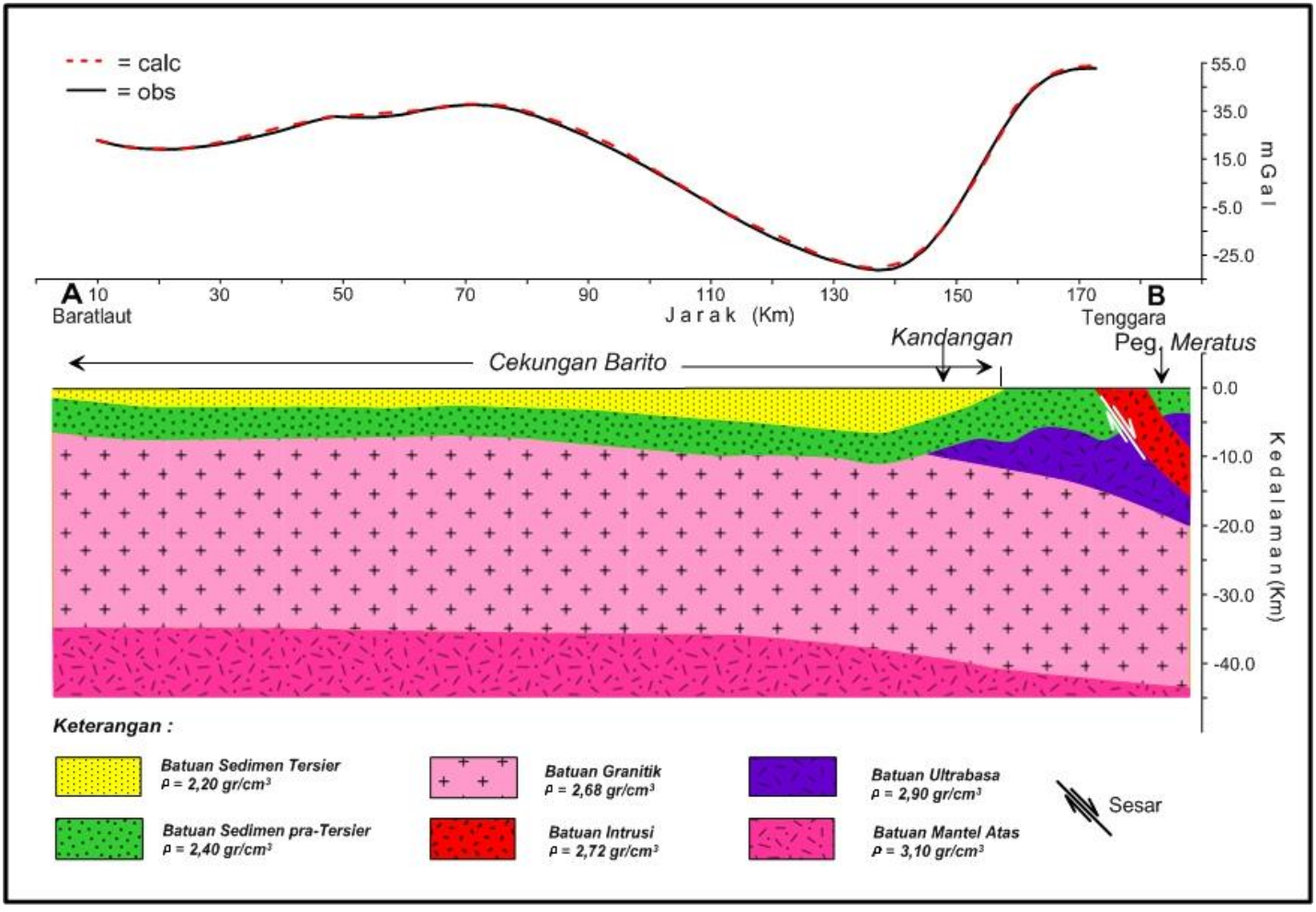

Gambar 4. Model Struktur Kerak Sepanjang Lintasan A-B ${ }^{[12]}$

Berdasarkan hasil model penampang pada Gambar 4 di atas ini, maka anomali rendah positip menempati bagian barat sampai tengah lintasan A-B, sedangkan anomali rendah negatip (hingga $-25 \mathrm{mGal}$ ) menempati bagian timur, tetapi di ujung bagian timur dengan nilai anomali Bouguer naik secara tajam dari $-25 \mathrm{mGal}$ hingga $+55 \mathrm{mGal}$.

Dalam model penampang gayaberat dengan rapatmassa $3,10 \mathrm{gr} / \mathrm{cm}^{3}$ mewakili Mantel Atas, 2,68 gr/ $\mathrm{cm}^{3}$ sebagai cerminan batuan dasar Granitik, sedimen pra-Tersier dan Tersier ditunjukan oleh batuan rapatmassa masing-masing $2,40 \mathrm{gr} / \mathrm{cm}^{3}$ dan $2,20 \mathrm{gr} / \mathrm{cm}^{3}$ [11]. Selain itu batuan Ultrabasa yang tersingkap di pegunungan Meratus memiliki rapatmassa 2,90 gr/ $\mathrm{cm}^{3}$ yang menumpang di atas batuan Granitik dan diterobos oleh batuan intrusi Granit (sesar) yang berhubungan dengan proses tektonik di daerah tersebut 
dengan rapatmassa 2,72 gr/ $\mathrm{cm}^{3}$ sebagaimana tampak pada Gambar 4. Sedangkan bagian barat sampai tengah, batuan sedimen dialasi oleh batuan Granitik.

Anomali gayaberat rendah positip di bagian barat hingga tengah dari lintasan A - B disebabkan oleh adanya lapisan sedimen dangkal, sedangkan di bagian timur atau sisi bagian barat pegunungan Meratus, memiliki nilai anomali rendah sekitar $-25 \mathrm{mGal}$ disebabkan oleh lapisan sedimen yang cukup tebal dan dari hasil analisis data penampang gayaberat di daerah ini menunjukkan bahwa anomali rendah tersebut dikenal sebagai Cekungan Barito.

\section{KESIMPULAN}

Berdasarkan data hasil konfigurasi Cekungan Barito berdasarkan analisis data gayaberat, maka dapat ditafsirkan bahwa pada bagian poros utama cekungan ini, batuan dasar Granit pra-Tersier berada pada kedalaman sekitar $11 \mathrm{~km}$. Di bagian Cekungan Barito, diisi oleh sedimen Tersier Tua setebal $5 \mathrm{~km}$ dan sedimen Tersier Muda setebal $6 \mathrm{~km}$ yang berada di bagian paling atas.

Pada batuan dasar Granit pra-Tersier secara sangat perlahan naik mendekati permukaan pada kedalaman $6-7 \mathrm{~km}$, sedangkan di atas batuan dasar diisi oleh batuan Sedimen Tersier Tua setebal $5 \mathrm{~km}$ yang ditutup oleh batuan Sedimen Tersier Muda setebal 1 - 2 $\mathrm{km}$. Adanya penebalan batuan Sedimen yang berada di sisi sepanjang pegunungan Meratus diduga disebabkan oleh proses tektonik yang kuat di daerah ini.

\section{UCAPAN TERIMAKASIH}

Penulis mengucapkan terima kasih kepada Kepala Pusat Penelitian dan Pengembangan Geologi Kelautan yang telah memberikan kesempatan untuk mempublikasikan hasil pemetaan gayaberat Bouguer daerah Amuntai dan sekiatanya, Kalimanatan Selatan. Tak lupa ucapan terima kasih kepada teman-teman dan tim editor Indonesia Journal of Applied Physics yang telah memberikan saran dan masukan untuk tulisan ini.

\section{DAFTAR PUSTAKA}

1 Hutabarat, M. 1994. Peranan Tektonik Dalam Akumulasi Hidrokarbon di daerah Tanjung Raya Cekungan Barito Kalimantan Selatan. Pertamina : Dinas Eksplorasi MIGAS EP, pp. 1-3.

2 Kusuma, I. dan Darin, T. 1989. The Hydrocarbon Potential of the Lower Tanjung Formation. Barito Basin. Kalimantan Selatan, in Proceedings of IPA 18 ${ }^{\text {th }}$, Annual Convention, pp. 107-138.

3 Ott, H.L. 1987. The Kutai Basin - Unique Structural History. Jakarta : Proceedings $16^{\text {th }}$ Annual Convention. Indonesia Petroleum Association, pp. 307-316.

4 Heryanto, R. dan Sanyoto, P. 1994. Peta Geologi Lembar Amuntai Kalimantan Selatan Skala 1:250.000. Pusat Penelitian dan Pengembangan Geologi, Bandung.

5 Kingston, D.R., Dishroon, C.P. and Williams, P.A. 1983. Hydrocarbon Plays and Global Basin Classification. AAPG Bulletin 67 (12), pp. 2194-2198.

6 Satyana, A.H. and Silitonga, P.D. 1994. Tectonic Reversal in East Barito Basin, South Kalimantan : Consideration of the types of Inversion Structures and Petroleum System Sygnificance. Proceeding of Indonesia Petroleum Association $23^{\text {nd }}$ Annual Convention, pp. 57-74. 
7 Sapiie, B. and Rifiyanto, A. 2017. Tectonic and Geological Factor Controlling Cleat Development in Barito Basin, Indonesia. Journal Engineering Technology Science ITB, Vol.49, No.3, pp. 322-339.

8 Mirnanda, E. 2000. Laporan Pemetaan Gayaberat Lembar Amuntai, Provinsi Kalimantan Selatan. Pusat Penelitian dan Pengembangan Geologi, Bandung (tidak dipublikasikan).

9 Mirnanda, E., Wahyono, H., Hayat D.Z. dan Sartono. 2003. Peta Anomali Bouguer Lembar Amuntai (Kalimantan) Skala 1:250.000. Pusat Penelitian dan Pengembangan Geologi, Bandung (terbit).

10 Mirnanda, E. dan Supriyadi. 2006. Anomali Gayaberat Kalimantan Bagian Selatan Hubungannya dengan Cekungan dan Mineralisasi. Jurnal MIPA, ISSN 0215-9945, Fakultas MIPA : Universitas Negeri Semarang, Vol. 29, No.1.

11 Telford, W.M., Geldart, L.P., Sheriff, R.E. and Keys. D.A. 1990. Applied Geophysics Second Edition. New York : Cambridge University Press.7.

12 Pedley, R.C. 1991. Interactive 2.5D Gravity and Magnetic Modelling Program (Gravmag) User Manual. British Geological Survey, Keyworth, Notingham 